\title{
The System \& Development of Human Resource Management
}

\author{
Chetan Kumkar ${ }^{1}$, Dr. N. R.Rajhans ${ }^{2}$ \\ M. Tech Project Management, \\ College of Engineering, Pune
}

\begin{abstract}
The System \& Development of HRM has been presented in this paper clearly. Thus the study is going to identify the points distinguishing between HRM and will also evaluate 'hard' and 'soft' approaches to HRM, illustrates but diversity could be a drawback in Human Relations (HR) study. It's outlined with a discussion relating to 'hard' and 'soft' models of HRM and its implications for the human resource manager. Why and how personnel functions should reorient their activities to require an additional strategic and developmental approach to human resource management (HRM). Currently, human resource (HR) policies are, within the main, centrally determined and developed. There's a commitment to decentralize and devolve hr responsibilities. Allied with this extra strategic focus is that the concept of devolution of responsibility for each day human resource matters to line managers. the requirement for wise analysis in connectedness the professionalization of HRM and so the devolution of HR responsibilities has been given specific stress by the recent publication of the fifth national social partnership agreement likewise as the Programmed for Prosperity and Fairness (2000).
\end{abstract}

Keywords: HRM, System of Human resource management, Functions of HR

\section{Introduction}

A Human Resources Management System (HRMS) or, refers to the systems and processes at the intersection between human resource management (HRM) and information technology. [1] It merges HRM as a discipline and, specifically, it's basic hr activities and processes with the data technology field, whereas the programming of information processing systems evolved into standardized routines and packages of enterprise resource coming up with (ERP) software. On the entire, these ERP systems have their origin from software that integrates data from completely different applications into one universal database. The linkage of its financial and human resource modules through one database is that the most significant distinction to the individually- and proprietarily-developed predecessors, that makes this software application each rigid and versatile.

A Human Capital Management solution, Human Resources Management System (HRMS), or Human Resources information system (HRIS), as it is usually referred to as, is that the crossing of $\mathrm{hr}$ systems and processes with information technology. The wave of technological advancement has revolutionized each and every area of life these days, and $\mathrm{hr}$ in its totality was not left untouched. Early systems were narrow in scope, usually targeted on one task, like improving the payroll method or following employees' work hours. Today's systems cover the complete spectrum of tasks related to Human Resources departments, as well as following \&amp; improving method efficiency, managing organizational hierarchy, and simplifying financial transactions of every kind. In short, as the role of Human Resources departments enlarged in complexity, hr technology systems evolved to suit these needs Following is that the method diagram for HRM. [2]
The most important operation of human resources (HR) departments is administrative and is common to all organizations. Organizations may also have formalized selection, evaluation, and payroll processes. Management of "human capital" progressed to an essential and complicated method. The HR function consists of following available employee information which traditionally includes personal histories, skills, capabilities, accomplishments and salary. To cut back the manual workload of these administrative activities, organizations began to electronically automate several of these processes by introducing specialized human resource management systems. HR executives rely on internal or external IT professionals to develop and maintain an integrated HRMS. [3] Before client-server architectures evolved in the late 1980 s, many HR automation processes were relegated to mainframe computers that could handle large amounts of data transactions. In consequence of the high capital investment necessary to buy or program proprietary software, these internally developed HRMS were limited to organizations that possessed a large amount of capital. The advent of client-server, application service provider, and software as a service (SaaS) or human resource management systems enabled higher administrative control of such systems. Presently human resource management systems encompass:

- Payroll

- Time and attendance

- Performance appraisal

- Benefits administration

- HR management information system

- Recruiting/Learning management

- Performance record

- Employee self-service

- Scheduling

- Absence management

- Analytics

- Employee Re-assign module 
International Journal of Science and Research (IJSR)

ISSN (Online): 2319-7064

Index Copernicus Value (2013): 6.14 | Impact Factor (2014): 5.611

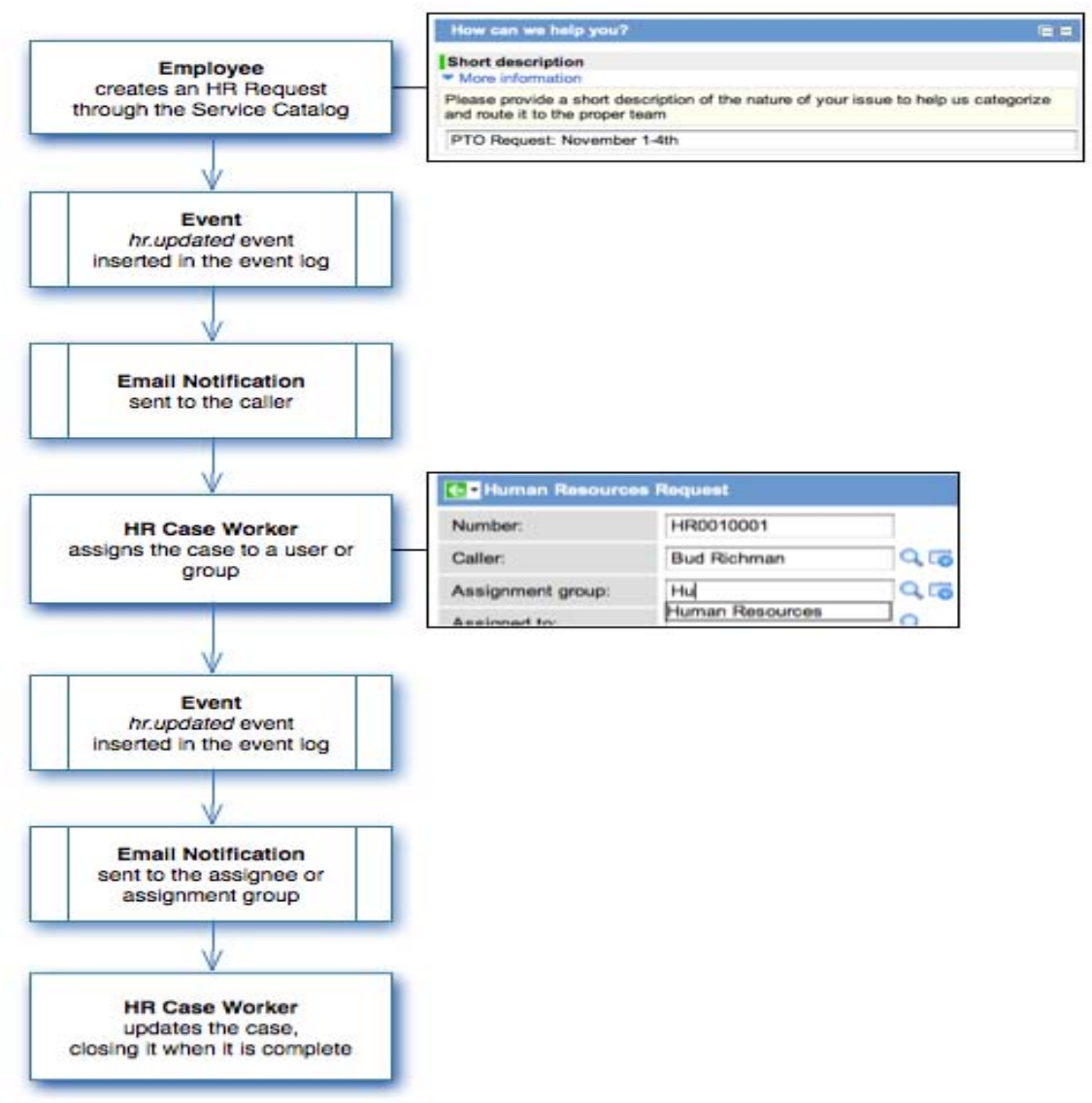

Figure 1: Process of HRM

By gathering data on employee time and attendance, calculating various deductions and taxes, and generating periodic pay cheque and employee tax reports the payroll module automates the pay process. Time keeping modules to calculate automatic deposit and manual cheque writing capabilities are used as well data is fed from the HR. This module can encompass all employee-related transactions as well as integrate with existing financial management systems.

The standardized time and work related efforts are collected by the time and attendance module. The most advanced modules provide broad flexibility in data collection methods, labor distribution capabilities and data analysis features. The primary functions are Cost analysis and efficiency metrics.

The benefits administration module provides a system for organizations to administer and track employee participation in benefits programs. Insurance, compensation, profit sharing and retirement are typically encompassed by these.

The HR management module is an important part that covers a lot other HR aspects from application to retirement. The system records basic demographic and address data, selection, training and development, capabilities and skills management, compensation planning records and other related activities. Leading edge systems provide the ability to "read" applications and enter relevant data to applicable database fields, notify employers and provide position management and position control.
The recruitment, placement, evaluation, compensation and development of the employees of an organization are involved in Human resource management. Initially, businesses used computer based information systems to:

- produce pay checks and payroll reports;

- maintain personnel records;

- Pursue talent management.

One of the most primary methods employed by HR departments to garner potential candidates for available positions within an organization is Online Recruiting. Talent management systems typically encompass:

- analyzing personnel usage within an organization;

- identifying potential applicants;

- recruiting through company-facing listings;

- Recruiting through online recruiting sites or publications that market to both recruiters and applicants.

The Rise in Development of a dedicated applicant tracking system, or 'ATS', module is because of the significant cost incurred in maintaining an organized recruitment effort, cross-posting within and across general or industry-specific job boards and maintaining a competitive exposure of availabilities.

A system for organizations to administer and track employee training and development efforts are provided in training module. "Learning Management System" (LMS) is a system that if a standalone product, allows HR to track education, 


\section{International Journal of Science and Research (IJSR) \\ ISSN (Online): 2319-7064}

Index Copernicus Value (2013): 6.14 | Impact Factor (2014): 5.611

qualifications and skills of the employees, as well as outlining what training courses, books, CDs, web based learning or materials are available to develop which skills. Courses can then be offered in date specific sessions, with delegates and training resources being mapped and managed within the same system. Sophisticated LMS's allow managers to approve training, budgets and calendars alongside performance management and appraisal metrics.

The employee self-service module allows employees to query HR related data and perform some HR transactions over the system. Employees may query their attendance record from the system without asking the information from HR personnel. The module also lets supervisors approve O.T. requests from their subordinates through the system without overloading the task on HR department.

Many organizations have gone beyond the traditional functions and developed human resource management information systems, which support recruitment, selection, hiring, job placement, performance appraisals, employee benefit analysis, health, safety and security, while others integrate an outsourced applicant tracking system that encompasses a subset of the above.

Assigning Responsibilities Communication between the Employees.

The Analytics module enables organizations to extend the value of an HRMS implementation by extracting HR related data for use with other business intelligence platforms. For example, organizations combine HR metrics with other business data to identify trends and anomalies in headcount in order to better predict the impact of employee turnover on future output.

There are now many types of Human Resources Management System (HRMS) or Human Resources Information System (HRIS) some of which are typically local-machine based software packages the other main type is an online cloud-based system which can be accessed via a web browser.

The Staff Training Module enables organizations the ability to enter, track and manage employee and staff training. Each type of activity can be recorded together with the additional data. The performance of each employee or staff member is then stored and can be accessed via the Analytics module.

Employee Re-Assign module is a recent additional functionality of HRMS. This module has the functions of Transfer, Promotion, Pay revision, Re-designation, Deputation, Confirmation, Pay mode change and Letter Formats.

\section{Objectives of this Study}

- Define what is meant by the term 'human resource management'

- Understand the roles of line managers and human resource managers

- In managing people
- Outline the range of activities with which practitioners of human resource

- Management are likely to be involved

- Demonstrate how human resource management can make a difference

- By adding value to an organization

- Outline some of the current issues facing hr managers.

\section{HRM Activities}

- Recruitment and selection

- Learning and talent development

- Human resource planning

- Provision of contracts

- Provision of fair treatment

- Provision of equal opportunities

- Managing diversity

- Motivating workers to achieve improved performance

- Employee counselling

- Talent management

- Employee wellbeing

- Payment and reward of employees

- Health and safety

- Disciplining individuals

- Dealing with grievances

- Dismissal

- Redundancy

- Negotiation

- Encouraging involvement and engagement

- Adding value

- Ethics and corporate responsibility

- Knowledge management

- Change management

- Managing cross-cultural issues or international hrm.

\section{Problem Identification}

\subsection{Political and Economic}

The state of the national and global economy has a direct impact on all types of organization and will inevitably influence their people practices and strategies. In the simplest of terms, consumer spending power dictates what goods and services need to be produced, which has an impact on employers' employment decisions and intentions. The CIPD (2009b) emphasize the need for HR practitioners to understand the economy and its impact on the labor market. The economy is affected by the interplay of a wide variety of factors including rates of unemployment, the demand for goods and services as reflected by consumer decisions on spending and saving, the costs of importing and exporting goods, and the policies of the political party in power on issues such as inflation. The ability of the Government to influence employment decisions and consumer spending as strategies to improve the economic outlook has been a matter of debate in recent years.

\subsection{Social and Demographic}

Though understandably the economic situation has taken precedence recently there are other social and demographic 


\section{International Journal of Science and Research (IJSR) \\ ISSN (Online): 2319-7064}

Index Copernicus Value (2013): 6.14 | Impact Factor (2014): 5.611

factors that also have an effect on the HR department and the HR techniques it uses. Most western countries are experiencing falling birth rates which combined with improvements in health and medical advances results in an ageing workforce. The age at which individuals will be able to access their pensions in the UK is due to increase between 2010 and 2020 so that men and women's state pension age will equalize at 65 by November 2018. The previous Labor government wanted to increase the state pension age further by stages and set this out in the Pensions Act 2007 so that by 2046 the state pension age would rise to 68 . However, the Coalition government feels that this should happen even sooner and recent legislation has already abolished the default retirement age and made it illegal to dismiss workers just because they reach a certain age. The pension age for everyone increases to 66 on 6 April 2020.

\subsection{IT}

If you glance through any journal relating to human resource management nowadays, you will find countless advertisements relating to the various ways that information technology (IT) can assist those in the HR department to do their jobs. These include: systems for e-recruitment, online short listing of applicants, online performance management and appraisals, e-learning, online psychometric testing, as well as IT systems to help with payroll, employment data, recruitment administration, references and pre-employment checks. There are also some large organizations which use HR shared service centers where they bring many of the HR services together and use technology such as email, a company intranet or telephones to provide HR information in order to deal with HR queries and provide expert advice for people working at various sites, sometimes in different countries.

\subsection{Human Capital}

By the early 2000s several new areas were starting to be of concern to those involved in managing people. The term 'human capital' was being discussed and, in particular, ways to measure human capital was an area of concern to some employers. The government set up a strategy group to examine the concept of human capital and created the Accounting for People Task Force to investigate it. Professor Scarborough and the CIPD Human Capital Task Force (2003) defined the term 'human capital' as 'the contribution of people [their skills and knowledge] in the production of goods and services.'

\section{Scope of this Study}

The value of human resources can't be over-emphasized. During the last two decades, computerized machines are replacing human beings in the industries. As a result of this, the functions of personnel management have also taken a new turn. The proper or improper uses of the different factors of production depend on the wishes of the human resources. Hence, besides other resources, human resources need more development.

The personnel department in this case can be compared with the human brain. The different parts of the body will not work if brain stops working. If the labor force of an undertaking is co-operative, a strong organization can be built. The following points bring about the importance of personnel function is management.

- The personnel manager is regarded by the employees as protector of their interests.

- In order to provide stability, personnel policies are developed by personnel manager.

- Social or Human Approach: - This concept recognizes labor as a human being and also a significant part of the organization. This approach emphasizes that investment in labor can often prove to be more beneficial than investment in other asserts. If labor is treated properly, most of the problems will be automatically solved.

Importance of Management, Human Resource Management enables all persons to contribute most effectively to its purpose in the performance of their duties. It promotes individual development and encourages mutual confidence and under-standing between the employees and employers. It thus attains personal and social satisfaction which tends naturally to seek within their working environment.

It provides an invisible framework by which various individuals are fitted into an effective team. Human Resource Management is also concerned with assigning authority and responsibility to individuals with a view to communicate between experts at various levels, and to enforce accountability. It helps make possible the large and effective aggregations of employees. If Human Resource Management is to function correctly, the personal executive can reduce disagreements that arise regarding his place on the company team but also can help instruct others on their logical personal duties and relationships. Human Resource Management is not confined to industries but it has also equal importance in all types of offices laboratories, nonprofit institution and armed services.

\section{Conclusion}

The Background to HRM is been studied in here, as well as many other areas are introduced in which HR managers are presently working, and also introduced few of the topics that are been discussed along with the debates regarding the ever-changing roles of HR specialists. Current Thinking and research about HRM is been focused her and the extent to which various HRM strategies contribute to the organization being effective. Additionally emphasized the fact that line managers nowadays play important roles in many aspects of managing people. In reality, HR roles are very diverse and no one model explains them completely. In small or medium-sized organizations there will be HR practitioners who will deal with all aspects of HRM and who will regard themselves as generalists. In larger organizations there could also be a much greater degree of specialization and some will use business partners and may adopt a shared services approach alongside this. Wide selection of roles being adopted as HR departments adapted to meet new demands and continued to search for ways to add value to their organizations and contribute to their strategic objectives. This can continue as organizations notice and adapt completely different HR strategies to assist them to achieve

\section{Volume 4 Issue 12, December 2015}


success in response to the economic circumstances within which they notice themselves and as ways of leading and motivating their own often diverse workforces in situation specific ways.

\section{References}

[1] Johnason, P. (2009). HRM in changing organizational contexts. In D. G. Collings \& G. Wood (Eds.), Human resource management: A critical approach (pp. 19-37). London: Routledge.

[2] Collings, D. G., \& Wood, G. (2009). Human resource management: A critical approach. In D. G. Collings \& G. Wood (Eds.), Human resource management: A critical approach (pp. 1-16). London: Routledge.

[3] Paauwe, J., \& Boon, C. (2009). Strategic HRM: A critical review. In D. G. Collings, G. Wood (Eds.) \& M.A. reid, Human resource management: A critical approach (pp. 38-54). London: Routledge.

[4] Klerck, G. (2009). "Industrial relations and human resource management". In D. G. Collings \& G. Wood (Eds.), Human resource management: A critical approach (pp. 238-259). London: Routledge.

[5] Merkle, Judith A. Management and Ideology. University of California Press. ISBN 0-520-03737-5.

[6] Mayo, Elton (1945). "Hawthorne and the Western Electric Company" (PDF). Harvard Business School. Retrieved 28 December 2011.

[7] "About CIPD". Chartered Institute of Personnel and Development. Retrieved 22 December 2011.

[8] "About Cornell ILR". Cornell University School of Industrial and Labor Relations. Retrieved 2010-01-29.

[9] "About SHRM". Society for Human Resource Management. Retrieved 22 December 2011.

[10] Cappelli, Peter. "Why We Love to Hate HR ... and What HR Can Do About It". Harvard Business Review (July-August 2015). Retrieved 25 July 2015.

[11] O'Brien, Michael (October 8, 2009). "HR's Take on The Office". Human Resource Executive Online. Archived from the original on 18 December 2011. Retrieved 28 December 2011.

[12] "Catbert shows tougher side to human resources". Personnel Today. August 30, 2007. Retrieved 28 December 2011.

[13]Ulrich, Dave (1996). Human Resource Champions. The next agenda for adding value and delivering results. Boston, Mass.: Harvard Business School Press. ISBN 087584-719-6. OCLC 34704904 